фиброгастродуодеденоскопию (ФГДС) и эзофагогастродуоденоскопию (ЭГДС). Все пациенты получали консервативное лечение.

Результаты и их обсуждения: 40 (100\%) пациентов отмечали желтушность кожных покровов. $3(8,1 \%)$ пациента в анамнезе отмечали артериальную гипертензию. Синдром холестаза среди женщин отмечался у 22 (55\%) пациентов. Наличие сахарного диабета было выявлено у 13(32,5\%) пациентов, что требовалось консультация эндокринолога при назначении лечении. При УЗИ-исследовании наличие кист было выявлено у 38 (95\%) пациентов. При дополнительном проведении УЗИ почек у 9 $(22,5 \%)$ пациентов было выявлено наличие кист. При оценке размеров и количества установлено, что 34 (85\%) больных имели одиночные кисты диаметром от 4 до 10 мм. Множественные кисты имели 4 (7,5\%) пациента: у 1 (2,5\%) - диаметр составил от 7 до 18 мм, у 3 (5\%)- от 21 до 32 мм, что требовало малоинвазивного или операционного вмешательства, так как пациенты предъявляли жалобы со стороны органов брюшной полости и имели изменения в биохимическом анализе крови в виде синдрома холестаза.При дополнительном проведении УЗИ органов брюшной полости было у 2 (5\%) больных, было выявлено наличие гемангиом печени.

\title{
Выводы.
}

1. При обнаружении очагового образования кистозного характера в паренхиме печени по данным УЗИ необходимо дополнительное проведение УЗИ почек.

2. Кисты больших размеров способствуют появлению жалоб у пациента и развитию изменений в рутинных лабораторных и инструментальных методах исследования, что меняет тактику ведения больных.

3. При интерпретации биохимического анализа крови ООП выявляется синдром холестаза, что может свидетельствовать об ухудшении функции печени.

$$
* * *
$$

1. Морозова Т.Г., Кудрявцева А.В. Диагностическая значимость мультипараметрического ультразвукового исследования при диффузных и очаговых заболеваниях печени у пациентов гастроэнтерологического профиля // Сборник научных трудов по материалам международной научной конференции. - 2017 . - С. 17-19.

2. Колкин Я.Г.,. Момот Н.В, Хацко В.В., Шаталов А.Д., Павлов К.И. Компьютерная и МагнитноРезонанасная томография в диагностике очаговой патологии печени // Архив клинической медицины - 2010. № 1 .- С. 116-121

3. Агрызков А.Л. Малоинвазивная диагностика гемангиом печени/А.Л. Агрызков//Анналы хирургической гепатологии. -2002.-Т.7, № 1.-С. 247.

4. Баб'як Т.Е. Сучасніаспектидіагностики та лікуваннябактерійнихабсцесівпечінки: автореф. дис. на зобуття наук. ступеня канд. мед. наук: спец. 14.01.03 "Хірургія."/Т.Е. Баб'як. -Львів, 2003. - С. 19

5. Губергриц Н.Б. Доброкачественные опухоли печени/Н.Б. Губергриц, Н.С. Кабанец, В.Я. Колкина, М.А. Крюк//Укр. журнал хірургії. -2009. -№4. -С. 40-43.

\section{Чекрыгина В.В., Богачева А.B. \\ Критерии выбора витаминных добавок и препаратовдля детей младшего и среднего возрастов на примере города Оренбурга}

Оренбургский государственный медицинский университет (Россия, Оренбург)

doi:10.18411/spc-22-12-2017-28

idsp: 000001:spc-22-12-2017-28

Максимальное количество витаминов, которое потребляет организм, обусловлено генетически. Технический прогресс освободил человека от тяжелого физического труда и больших энерготрат, что привело к необходимости уменьшить 
объем потребляемой пищи. Вместе с тем потребность в витаминах осталась на прежнем уровне.

Сохраняются причины, которые способствуют развитию гиповитаминозных состояний у детей. Ускоренный метаболизм, вызванный ростом организма, зачастую неизбежные стрессы, не всегда сбалансированное питание, чрезмерные умственные нагрузки и прочее способствуют развитию состояний, при которых обычные дозы поступающих с пищей витаминов становятся неадекватными.

За последние 20 лет практически не находятся детей, оптимально обеспеченных всеми витаминами. У большинства (до 70\%) наблюдается сочетанный дефицит трех и более витаминов независимо от возраста, времени года и места проживания.

Настораживает, что дефицит витаминов обнаруживается не только зимой и весной, но и в летне-осенние периоды, что свидетельствует о формировании круглогодичного типа полигиповитаминоза.

Из-за недостатка витаминов снижается способность иммунной системы противостоять действию вирусов и бактерий. Особое значение дефицит витаминов и микроэлементов имеет для детей младшего и среднего возраста.

Теоретическая возможность обеспечить ребенка всеми необходимыми витаминами за счет исключительно натуральных продуктов питания выглядит довольно привлекательной, но в реальности она мало достижима.

Содержание витаминов в овощах и фруктах широко варьирует в различные сезоны. Содержание витаминов в пищевых продуктах невелико (от 10 до 100 мг/100 г) и зависит от следующих условий:времени года, условий выращивания овощей, способа хранения продукта, способа обработки продукта.

В летне-осенний период предпочтение отдается натуральным продуктам, являющимся источниками витаминов (свежим фруктам, овощам и ягодам, а также сокам и т.д.). Вместе с тем в России из-за низкого уровня жизни у подавляющего большинства населения среднее потребление свежих фруктов и ягод не превышает $15 \%$ от рекомендуемого количества.

Таким образом, диете принадлежит важная, но не определяющая роль в профилактике и лечении дефицита витаминов. Назначение детям поливитаминных комплексов с минералами имеет гораздо большее значение. При этом необходимо помнить, что продолжительный прием отдельных жирорастворимых витаминов в больших дозах сопряжен с риском реализации их токсического воздействия на организм (гипервитаминозы). Хотя избыток водорастворимых витаминов обычно успешно выводится с мочой, известны случаи их передозировки. Следовательно, наиболее предпочтительным является продолжительный прием специальных витаминно-минеральных комплексов, подобранных в строгом соответствии с возрастом.

Сегмент витаминов для детей делится на две части - лекарственные препараты (ЛС) и биологически активные добавки (БАД), за исключением витаминизированного детского питания. Необходимо отметить, что в настоящее время витаминизированные средства для детей, представленные на полках аптек и фарммаркетов, отличает широта ассортимента.

Лекарственные препараты занимают доминирующее положение в аптечной рознице витаминов для детей: на долю ЛС приходится $82 \%$ объема рынка, тогда как БАД аккумулируют 18\%.

Отметим, что существуют три поколения витаминных препаратов. Первое поколение: моноформы(например, аскорбиновая кислота); второе поколение комплекс витамеров- (например витамеры витамина В9 - фолиевая кислота, тетрагидрофолат); 
третье поколение - комплексы витаминов с микроэлементами и витаминоподобными веществами, другими эссенциальными микронутриентами.

Витамины на российском фармрынке представлены твердыми формами для перорального применения, жидкими и мягкими формами для перорального применения, а также инъекционными лекарственными формами. Показательно, что самые популярные среди юных потребителей лекарственные формы - это жевательные таблетки и таблетки для рассасывания, которые аккумулируют 76\% продаж сегмента БАД и $27 \%$ сегмента ЛС.

Нельзя попросту смешивать ингредиенты поливитаминного препарата - из-за химических реакций некоторые компоненты могут перейти в неактивные формы. Именно поэтому в процессе изготовления витаминно-минеральных композиций ингредиенты подготавливаются таким образом, чтобы ограничить контакты между ними.

В педиатрии витамины используются не только для поддержания собственно гомеостаза, но и для инициации всей программы развития ребенка. Например, дефицит витамина А задерживает развитие ткани, что может проявляться недостаточным ростом ребенка. Витамины, несомненно, необходимы для человеческого организма, особенно для развивающегося. Вопрос только, каких критериев стоит придерживаться при выборе витаминов для ребенка.

При изучении данного вопроса мы исследовали шесть крупных аптечных сетей города Оренбурга (Оренлек, Фрамленд-Оренбург, Данафарм, Мега, Бережная аптека, Фармакор), а так же интернет-аптеку (Аптека.ру).Провели интернет-опрос среди 78 мам имеющих детей в возрасте 3-6 лет.В результате было отобрано девять наиболее востребованных витаминных добавок и препаратов, такие как: «Компливит АКТИВные Мишки», «Вита Мишки», «Юнивиткидс», «Витрумкидс», «Умка Мультивит», «Пиковит», «Алфавит», «Мульти-табс», «Супрадин».

Критерием выборавитаминов послужили:

- оптимальный состав и дозы входящих ингредиентов, таблица 1;

- категория и группа препарата;

- индивидуальные свойства организма (гипоаллергенность препарата);

- удобная лекарственная форма препарата;

- стоимость препарата.

Таблице 1

Название препарата и его состав

\begin{tabular}{|c|c|c|c|c|c|c|c|c|c|}
\hline $\begin{array}{l}\text { Название } \\
\text { препарата }\end{array}$ & 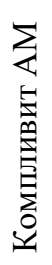 & 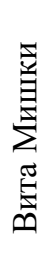 & 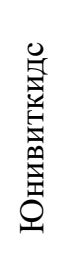 & 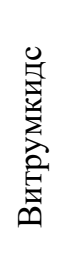 & 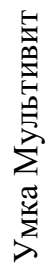 & 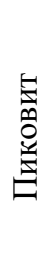 & 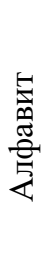 & 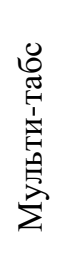 & 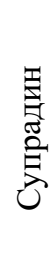 \\
\hline Витамин А & & + & & + & + & + & + & + & + \\
\hline Витамин $\mathrm{B}_{1}$ & + & & & + & & + & + & + & \\
\hline Витамин $\mathrm{B}_{2}$ & + & & & + & & + & + & + & \\
\hline Витамин $\mathrm{B}_{3}$ & + & & + & + & + & + & + & + & + \\
\hline Витамин $\mathrm{B}_{4}$ & & + & + & & & & & & \\
\hline Витамин $\mathrm{B}_{5}$ & + & + & & + & + & + & + & + & \\
\hline Витамин $\mathrm{B}_{6}$ & + & + & + & + & + & + & + & + & + \\
\hline Витамин $\mathrm{B}_{8}$ & & + & & & & & & & \\
\hline Витамин $\mathrm{B}_{9}$ & + & + & & & & + & & + & \\
\hline Витамин $\mathrm{B}_{12}$ & + & + & + & + & + & + & + & + & + \\
\hline
\end{tabular}




\begin{tabular}{|c|c|c|c|c|c|c|c|c|c|}
\hline Витамин C & + & + & + & + & + & + & + & + & + \\
\hline Витамин D & & + & & + & + & + & + & + & + \\
\hline Витамин Е & + & + & & + & + & + & & + & + \\
\hline Витамин Н & + & & & + & & & & & + \\
\hline Омега-3 & & & + & & & & & & \\
\hline Йод & & + & & + & & & + & + & \\
\hline Селен & & + & & + & & & + & + & \\
\hline Цинк & & + & & + & & & + & & \\
\hline Кальций & & & & + & & & + & & \\
\hline Магний & & & & + & & & + & + & \\
\hline Фосфор & & & & + & & & & + & \\
\hline Железо & & & & + & & & + & + & \\
\hline Медь & & & & + & & & + & & \\
\hline Марганец & & & & + & & & & & \\
\hline Хром & & & & + & & & & + & \\
\hline Марганец & & & & & & & + & & \\
\hline
\end{tabular}

Все исследуемые препараты относятся к категории биологически активных добавок, являются общеукрепляющими средствами и отпускаются безрецепта врача.

Очень важным критерием являлось гипоаллергенность препарата. Если малыш склонен к аллергическим реакциям, то следует заранее проверить, не вызовут ли те или иные витамины обострение. В результате исследования препараты разделились на три категории: аллергическая реакция выраженная (более 50\%), умеренная (встречалась меньше чем у $20 \%$ ) и ее отсутствие (не более $5 \%$ ).

Большое значение имело и лекарственная форма препарата, определяющая комфорт приема. Она должна быть максимально удобной, чтобы прием препарата не вызвал никаких проблем и стоит этот выбор представить ребенку. Лекарственная форма препаратов была представлена двумя видами: жевательный мармелад и жевательная таблетка.

Естественно немаловажным критерием явилась и стоимость препарата. Сравнительная характеристика по трем последним критериям представлена в таблице 2.

Таблица 2

Сравнительная характеристика препаратов

\begin{tabular}{|c|c|c|c|}
\hline & $\begin{array}{c}\text { Аллергическая реакция } \\
\text { на препарат }\end{array}$ & $\begin{array}{c}\text { Лекарственная } \\
\text { форма }\end{array}$ & $\begin{array}{c}\text { Стоимость препарата за } \\
\text { 30 шт. (руб) }\end{array}$ \\
\hline Компливит АМ & отсутствует & мармелад & $280-443$ \\
\hline Вита Мишки & умеренная & мармелад & $370-496$ \\
\hline Юнивиткидс & выраженная & мармелад & $363-503$ \\
\hline Витрумкидс & отсутствует & таблетка & $370-556$ \\
\hline Умка Мультивит & отсутствует & мармелад & $208-317$ \\
\hline Пиковит & умеренная & таблетка & $160-287$ \\
\hline Алфавит & отсутствует & таблетка & $281-422$ \\
\hline Мульти-табс & выраженная & таблетка & $331-514$ \\
\hline Супрадин & выраженная & мармелад & $323-405$ \\
\hline
\end{tabular}

Применение витаминов в практике педиатра имеет особое значение так как растущий и развивающийся организм ребенка наиболее значимо реагирует на их дефицит. Недостаток или отсутствие витаминов в организме приводит к нарушению обмена веществ, снижению физической и умственной работоспособности, быстрой утомляемости, отрицательно сказывается на росте и развитии детей. Полноценное и разнообразное питание является основой профилактики дефицита витаминов у детей различного возраста. Поливитаминные препараты можно рекомендовать как для профилактики, так и для лечения витаминодефицитных состояний. 
Однако следует помнить, что при бесконтрольном приеме витаминных препаратов в больших дозах могут развиться гипервитаминозы, которые в ряде случаев не менее опасны для здоровья детей, чем гиповитаминозы. При назначении детям поливитаминных препаратов необходимо использовать исключительно «детские» формы.

$$
* * *
$$

1. Паутова Е., Аптечный рынок витаминов для детей. ГЛС и БАД: Ремедиум. Журнал о российском рынке лекарств и медицинской технике. / Е. Паутова. - М.: Группа Ремедиум, 2008. - С. 16-20.

2. Громова О.А., Витамины детям: «за» и «против»:Педиатрическая фармакология / О.А. Громова. М.: ООО Издательство «Педиатръ», 2009. - С. 112-116.

3. Захарова И.Н., Коррекция дефицита витаминов и микроэлементов у детей дошкольного и школьного возраста: Вопросы современной педиатрии / И.Н. Захарова. - М.: ООО Издательство «Педиатръ», 2009. - С. 106-110. 